\title{
Simulation and Study of AODV Routing Protocol under CBR and TCP Traffic Source
}

\author{
Manish Singh Chaudhary and Varsha Singh
}

\begin{abstract}
A significant researched on TCP have been carried over wireless network. But, many of them related studies are limited to the cases with only one wireless link. The behaviors of TCP still have not well understood in the multi-hop wireless networks. In this traffic and mobility scenarios play an important role in evaluating the performance of these networks, despite comment and belief from various researches on TCP's weaknesses on MANET. A simulation was carried out to evaluate the performance of CBR over TCP on MANET using AODV routing protocol. Although $C B R$ and TCP have significant different manufacture behavior on MANET, these differences lead to significant performance of CBR over TCP with better throughput and packet delivery fraction and less average maximal end-to-end delay and less routing overhead. AODV was able to respond to link failure at high pause time, this led to significant performance in packets delivery. For our simulation we used a discrete event simulator known as Network Simulator version 2.34.
\end{abstract}

Index Terms-AODV, CBR, MANET, NS2, TCP.

\section{INTRODUCTION}

A Mobile Ad-Hoc Network (MANET) is a set of wireless mobile nodes which forms a temporary infrastructure-less network, communicate with each other and support de -centralized administration. Quick and easy deployment of ad-hoc network makes them feasible to use in battlefield environments, disaster relief and in conference. In MANET, nodes can move independently thus, each node function as a router and forward packet. Due to high node mobility network topology changes frequently. Therefore, routing in ad-hoc network becomes a more challenging task. Therefore it becomes recent research area in MANETs, Basically ad-hoc" is a multi-hop wireless networks have been proposed for nomadic computing applications. Many routing protocol and their algorithm have proposed in the RFC 4728 [1], RFC 2501 [2] for ad hoc network for finding routes, as it is in the literature [3]-[5], with the advance of wireless communication low cost and powerful trans-receiver are widely used in mobile application. The key requirements in all the above applications are reliable data transfer and congestion control, features that are generally supported by TCP. Unfortunately, TCP performs on wireless in a much less predictable way than on wired protocols. The main aim of this paper is to evaluate and compare the performance of CBR(constant bit rate ) over TCP (transmission control protocol ) traffic models using Ad hoc on Demand Distance

Manuscript received December 13, 2012; revised April 28, 2013.

The authors are with the National Institute of Technology, Raipur, G.E. Road, Raipur Chhattisgarh - 492010 India (e-mail: chaudharymanishsingh8@gmail.com,varsha_x_singh@yahoo.com)
Vector (AODV) [6], in variable pause time for a constant number of nodes to bring out their relative advantages. The main objective is to understand their internal mechanism of working and suggest in high stressful situations which one is preferred than the other.

\section{DESCRIPTION FOR AD-HOC ON DEMAND DistANCE VECTOR (AODV) ROUTING PROTOCOL FOR AD-HOC NETWORK}

The Ad-hoc On-demand Distance Vector routing protocol [1]-[3] enables multi-hop routing between the participating mobile nodes wishing to establish and maintain an ad-hoc network. AODV is a reactive protocol based upon the distance vector algorithm.

The algorithm uses different types of messages to discover and maintain links. Whenever a node wants to try and find a route to another node it broadcasts a Route Request (RREQ) to all its neighbors. The RREQ propagates through the network until it reaches the destination or the node with a fresh enough route to the destination. Then the route is made available by uncasing a RREP back to the source.

The algorithm uses hello messages (a special RREP) that are broadcasted periodically to the immediate neighbors. These hello messages are local advertisements for the continued presence of the node, and neighbors using routes through the broadcasting node will continue to mark the routes as valid. If hello messages stop coming from a particular node, the neighbor can assume that the node has moved away and mark that link to the node as broken and notify the affected set of nodes by sending a link failure notification (a special RREP) to that set of nodes.

\section{Mobile Ad-Hoc Network Performance Metrics}

Performance of proposed protocol is evaluated using the following metrics:

\section{A. Packet Delivery Ratio}

Packet delivery fraction is the ratio of the numbers of packets originated by the CBR sources to the number of packets received by the CBR sinks at the final destinations.

\section{B. Average End-to-End Delay of Data Packets}

This includes delays caused by buffering of data packets during route discovery, queuing at the interface queue, retransmission delays at the MAC.

\section{Number of Dropped Data Packets}

Packet loss occurs when one or more packets of data travelling across a computer network fail to reach their 
destination.

\section{Routing Overhead (RO)}

It is the total number of routing packets transmitted by network layer nodes before it reach to the destination.

\section{E. Throughput}

The throughput of the protocols can be defined as percentage of the packets received by the destination among the packets sent by the source. The throughput is measured in bits per second (bit/s or bps).

This simulation analysis is made from the graph sources. Here we analyze various parameters with respect to varying pause times.

\section{PREVIOUS WORKS}

Several performance evaluations of MANET routing protocols using CBR traffic have been done in the literature [7]-[11] by considering various parameters such as mobility, network load and pause time due to the comment and belief of the TCP's weaknesses in MANET. B. R. Arun et al., [9] have analyzed the performance of various protocols using VBR traffic in Ad-hoc networks and have shown that reactive protocols performs better than proactive protocols. Chander shekher [10] analyzed the performance of various routing protocols for ad-hoc networks using TCP traffic for a limited scenario.

As many analysis reveal that the poor performance by TCP for a network including a wireless link because Wireless channels are immensely noisy, so that packet losses are more frequent in wireless networks than in wired networks (TCP was designed for static networks). TCP does not differentiate between congestion-related packet drops and transmission failures at link layer. TCP treats all packet losses as indicators of network congestion, and triggers the congestion control mechanism. Consequently, transmission failures at the MAC layer cause the activation congestion control in TCP, and reduces the throughput

Despite the fact that considerable simulation work has been done, still more investigation is needed in the performance of the traffic and mobility models and comparison between them using routing protocols with the same metric parameters and specifications. [12] Evaluates performance of CBR and TCP traffic models using DSR routing protocol .our focus on same with the use of AODV protocol with more in detail analysis.

\section{Simulation SetuP}

For simulation we have used NS-2.34 [13], [14] which is a discrete even simulator in the platform Linux Ubuntu 11.10.We used topology area 600x600 meters with simulation time of 200 seconds, sending rate of 3 packets/second and transmission range of 250 meters. The simulation is run using these scenarios with CBR and TCP traffic patterns for AODV protocols. Simulations are carried out by varying the number of pause time $0,20,30$ and 50 sec.

\section{Simulation AND PERFORMANCE ANALYSis}

In this paper, we have taken two different traffic scenarios CBR and TCP with different pause time. Simulation analysis has been made between AODV protocol. Identical mobility pattern are used across protocols to gather fair results.

\section{A. Simulation Parameter for CBR and TCP Scenario}

In the first scenario, we have chosen the simulation based on CBR traffic pattern. Parameters of this scenario are summarized in table I. CBR sources are used that started at different Pause times

Here, TCP sources are used which use flow and error control with retransmission feature

\section{B. Random Waypoint Mobility Model}

TABLE I: SIMULATION SCENARIOS

\begin{tabular}{|l|l|l|}
\hline S. No. & \multicolumn{1}{|c|}{ Parameter } & \multicolumn{1}{c|}{ Value } \\
\hline $\mathbf{1}$ & Routing Protocols & AODV \\
\hline $\mathbf{2}$ & MAC Layer & 802.11 \\
\hline $\mathbf{3}$ & Terrain Size & $600 x 600$ \\
\hline $\mathbf{4}$ & Nodes & 60 \\
\hline $\mathbf{5}$ & Node Placement & Random \\
\hline $\mathbf{6}$ & Mobility Model & Random Way Point \\
\hline $\mathbf{7}$ & Data Traffic & CBR, TCP \\
\hline $\mathbf{8}$ & Simulation Time & 200 second \\
\hline $\mathbf{9}$ & Pause Time & $0,20,30,50$ \\
\hline $\mathbf{1 0}$ & Speed & 15 ms \\
\hline $\mathbf{1 1}$ & Seed & 1 \\
\hline $\mathbf{1 2}$ & Connection rate & 3 packet/second \\
\hline
\end{tabular}

In random waypoint mobility model, the nodes moves randomly and selects a position, moves towards it in a straight line at a constant speed that is randomly selected from a range, and pauses at that destination. The node repeats this, throughout the simulation.

\section{Simulation Results}

In this section, we present our simulation result to compareand evaluate the performance of CBR over TCP on MANET using AODV routing protocol. The Simulation was run at different pause times of 0, 20, 30, 50 with different packet sizes were sent with different traffic models.

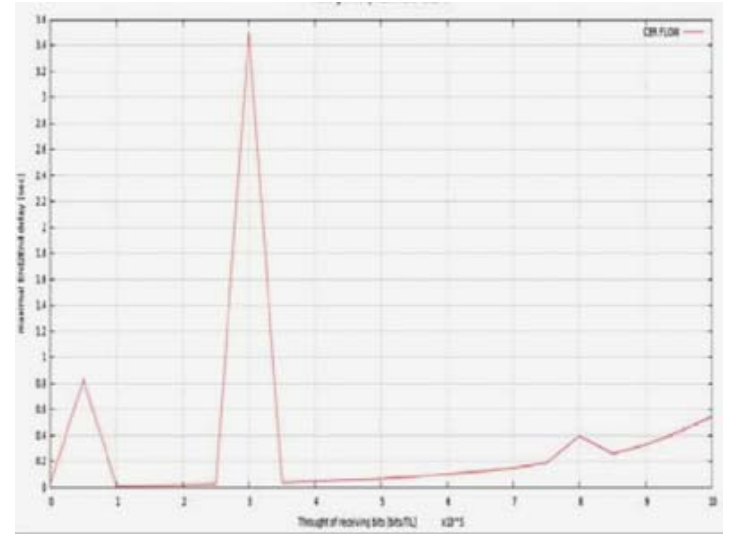

Fig. 1(a). Maximal E2E delay vs. throughput (x10^5 bits/s) for CBR FLOW. 
Fig. 1(a) and 1(b) shows throughputs of receiving bits Vs maximal end-to-end delay. From the figure it has been observed that at pause time of 0 seconds (i.e. low pause time) CBR performed better than TCP with high throughputs of receiving packets in bits with packet delivery fraction 99.44\% and less average maximal end-to- end delay of 0.036859 seconds and less routing overhead 8364 packet compared to 0.72299 seconds of e2e delay in TCP. (See table 3)The rise in the delay is due to the initial routing discovery mechanism of the AODV routing protocol.

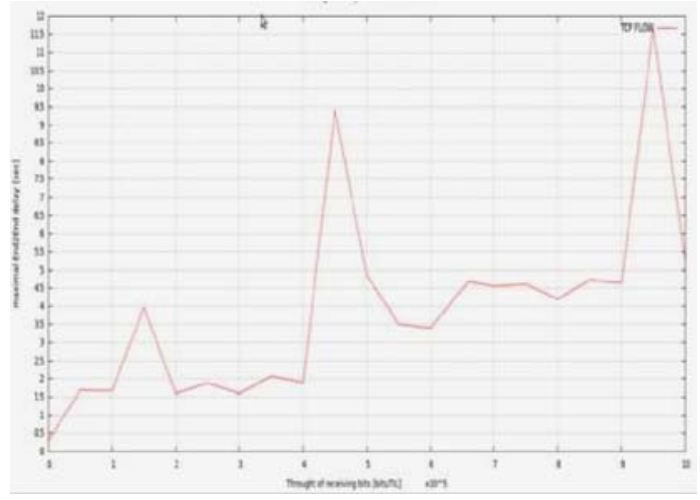

Fig. 1(b). Maximal E2E delay vs. throughput (x10^5 bits/s) for TCPFLOW.

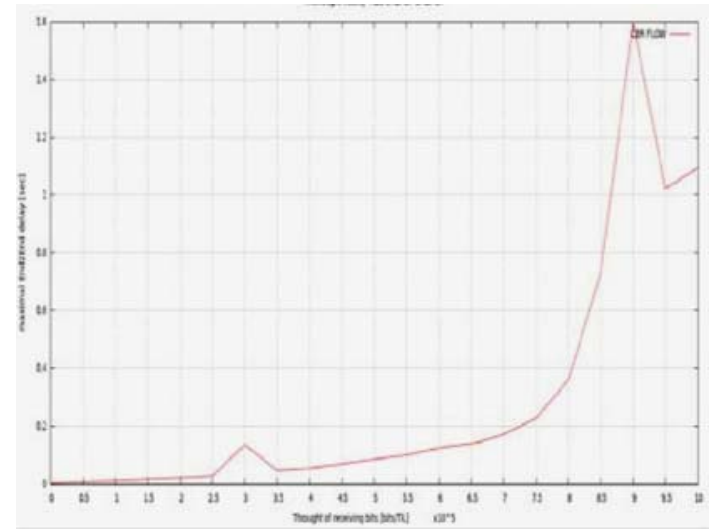

Fig. 2(a). Maximal E2E delay vs. throughput (x10^5 bits/s) for CBR FLOW

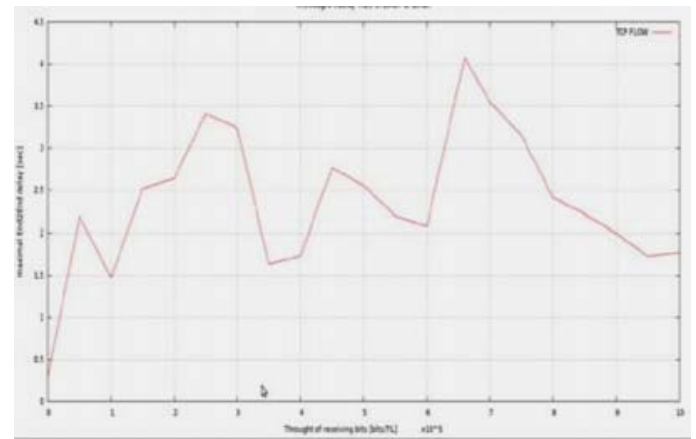

Fig. 2(b). Maximal E2E delay vs. throughput (x10^5 bits/s) for TCP FLOW.

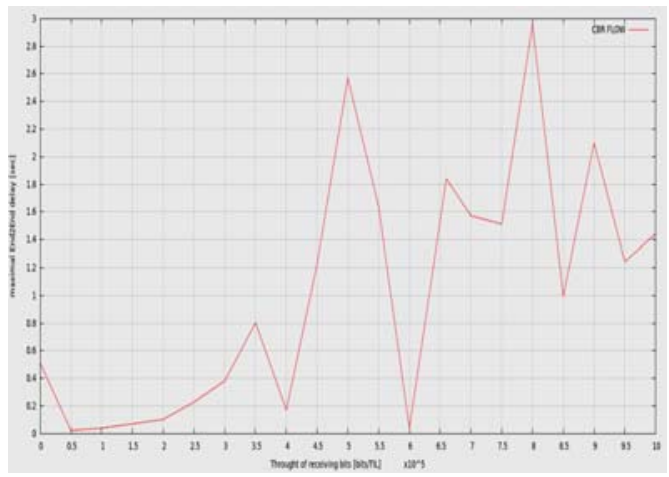

Fig. 3(a). Maximal E2E delay vs. throughput (x10^5 bits/s) for CBRFLOW.
As the pause time increases to 20 seconds, CBR has a better throughputs and packet delivery fraction $97.76 \%$ less routing overhead 8791as well as have less average maximal end-to-end delay (see table III) compared to TCP with packet delivery 96.34\% and require more routing overhead 11053 packets but still TCP was able to deliver reasonable amount of packets successfully despite its delays transmission. CBR has an average maximal end-to-end delay of 0.095913 seconds compared to 0.81655 seconds of TCP (see Fig. 2a and $2 b)$.

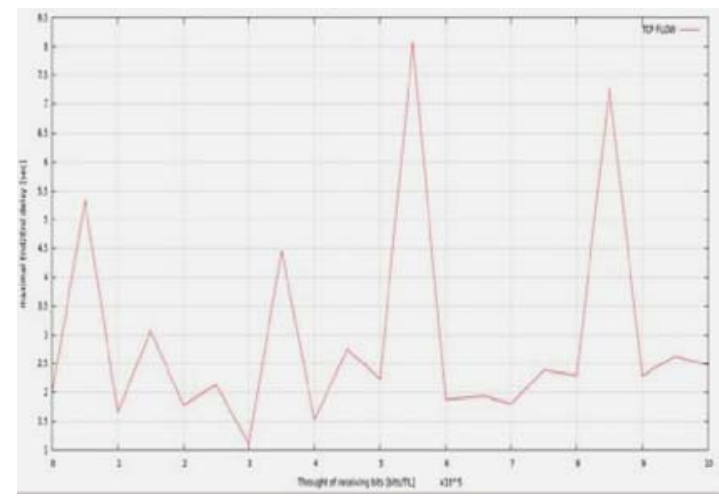

Fig. 3(b). Maximal E2E delay vs. throughput (x10^5 bits/s) for TCP FLOW.

As the pause time increases to 30 seconds, CBR has again achieve a better throughputs and less average maximal end-to-end delay with packet delivery fraction $99.43 \%$,less overhead 4994 it just half that require by TCP 8444 packets route overhead (see Table III). CBR has an average maximal end-to-end delay of 0.020134 seconds compared to 0.82571 seconds of TCP (See Fig. 3a and 3b).

As the pause time for which nodes wait on destination before moving to another destination, increases to 50 seconds (i.e. high pause time) while routing protocol tries to find the valid route to destination, TCP traffic model was unable to withstand the stress of the waiting at high load and mobility. It therefore, considers the waiting to be a sign of network congestion and consequently applies congestion control mechanism, which increases the maximal end-to-end delay exponentially consequently decreasing the throughput of receiving bits compared to CBR traffic models Therefore, increase in maximal end-to-end delay with increase in routing overhead of packet in network thus, decreases the percentage of the packets being delivered, despite AODV routing protocol's effort in justifying equal opportunities amongst the traffic models(See Fig. 4a and 4b).

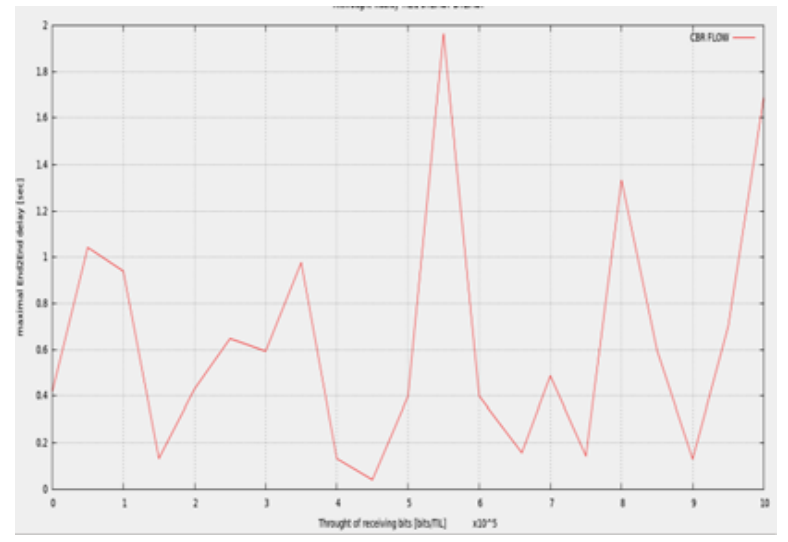

Fig. 4(a). Maximal E2E delay vs. throughput (x10^5 bits/s) for CBRFLOW. 


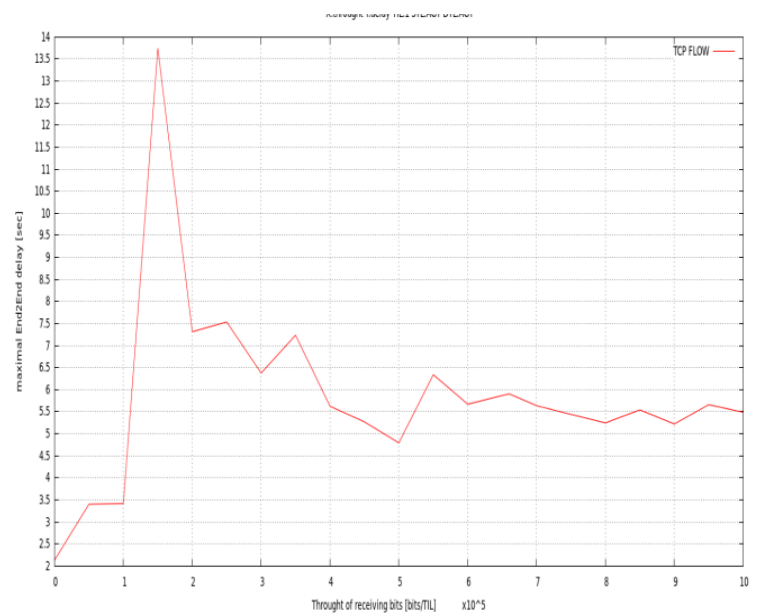

Fig. 4 (b). Maximal E2E delay vs. throughput (x10^5 bits/s) for TCP FLOW.

In general at both low and high mobility(low pause time and high pause time),in CBR routing overhead, maximal E2E delays, dropped packets falls drastically, but in TCP traffic models this is not the case in high pause times. (See table II and III). And this is attributed to the principles operation of AODV routing protocol which stores one routes to destination in its table-driven framework and destination sequence number to prevent loops and determine route freshness, in case of link failure it uses predecessor list, RERR packets reach all nodes using a failed link on its route to any destination., then it will initiate another route discovery. But there is considerable good response of AODV routing protocol to link failure at both low and high mobility before the TCP's congestion mechanism responds, and packets were successfully delivered while packets lost is due to increased in routing overhead as well as maximal end-to-end delay, time-to- live (TTL) of routing protocol and end of simulation time

The Table II and Table III below shows the descriptions of the average end-to-end delay, packets dropped, routing overhead and packet delivery fraction of both CBR and TCP traffic models with respect to pause time.

TABLE II: SUMMARY OF AVERAGE END-TO-END DELAY

\begin{tabular}{|c|c|c|c|c|}
\hline Pause time & \multicolumn{2}{|c|}{ Average End-to-End } & \multicolumn{2}{c|}{ Dropped Packet (in } \\
\hline (second) & \multicolumn{2}{|c|}{ delay (second) } & \multicolumn{3}{c|}{ byte) } \\
\hline & CBR & TCP & CBR & TCP \\
\hline 0 & .036859 & .72299 & 127 & 820 \\
\hline 20 & .095913 & .81655 & 117 & 535 \\
\hline 30 & .020134 & .82571 & \multirow{2}{*}{114} & 631 \\
\hline 50 & .051242 & .70975 & 91 & 567 \\
\hline
\end{tabular}

TABLE III: SUMMARY OF PACKET DELIVERY FRACTION

\begin{tabular}{|c|c|c|c|c|}
\hline Pause time & \multicolumn{2}{|c|}{ Routing overhead } & \multicolumn{2}{c|}{ Packet delivery } \\
\hline (second) & & & \multicolumn{2}{c|}{ fraction (\%) } \\
\hline & CBR & TCP & CBR & TCP \\
\hline 0 & 8364 & 12689 & 98.44 & 95.12 \\
\hline 20 & 8791 & 11053 & 97.76 & 96.34 \\
\hline 30 & 4994 & 8444 & 99.43 & 96.66 \\
\hline 50 & 6147 & 9836 & 97.89 & 95.65 \\
\hline
\end{tabular}

\section{CONCLUSION}

This paper investigated the performance evaluation result, it reveal that CBR perform better then TCP at both low and high pause time under different traffic and mobility model in term packet delivery fraction ,throughputs of receiving bits, require less routing overhead and have less packet drop as well as have less maximal E2E delay

Despite comment and belief by many researchers on TCP's weaknesses on MANET, TCP was able to deliver a reasonable number of packets in stressful conditions in high load and mobility condition but at the cost of maximum E2E delay and routing overhead.

Thus we observed that most packets loss are due to high route overhead as well as maximal end-to-end delay and time-to-live (TTL) bits of the routing protocol.

Further, we analyses that our results are comparable with those obtained by Dr. Panos Bakalis [12] for CBR and TCP traffic with few more parameter [13]-[14], we have analyzed using another reactive routing protocol that is AODV to determine how in more stress full condition the another reactive protocol will react, Our results give much closer view of the performance of the protocols for packet delivery fraction, average delay, and packet loss metrics than by them.

Future work will be to evaluate the performance of another routing protocol by varying the speed, simulation time, packet size and dimensions.

\section{REFERENCES}

[1] C. C. Perkins Dynamic MANET On-demand Routing Protocol (DYMO). [Online]. Available: http: //tools .ietf. org/ html/draft-ietf-manet-dymo,

[2] S. Corson and J. Macker, "Mobile Adhoc Networking (MANET), Routing Protocol Performance Issues and Evaluation Considerations," RFC 2501, January 1999.

[3] S. Das, C. E. Perkins, and E. Royer, “Ad Hoc On Demand Distance Vector (AODV) Routing,” IETF Draft, June 2002.

[4] E. M. Royer and C. K. Toh, "A Review of Current Routing Protocols for Ad Hoc Mobile Wireless Networks," IEEE Personal Communications, pp. 46-55, April 1999.

[5] R. Balakrishna, S. Jeyabalan, and U. RajeshwarRao, "Performance issues on AODV and DSDV for MANETS," Journal of Theoretical and Applied Information Technology, 2005

[6] C. E. Perkins and E. M. Royer, “Ad-Hoc On Demand Distance Vector Routing," in Proceedings of the 2nd IEEE Workshop on Mobile Computing Systems and Applications, New Orleans, LA, USA, pp 90-100, February 1999.

[7] J. Broch, D. A. Maltz, D. B. Johnson, Y. C. Hu, and J. Jetcheva, “A Performance Comparison of Multi-Hop Wieless Ad Hoc Network Routing Protocols," in Proc. of the ACM/IEEE International Conference on Mobile Computing and Networking (MobiCom), October 1998.

[8] I. Broustis, G. Jakllari, T. Repantis, and M. Molle. A Comprehensive Comparison of Routing Protocols for Large-Scale Wireless MANETs. [Online]. Available: http://www.cs.ucr.edu/mart /preprints /iwwan06.pdf.

[9] B. R. Kumar, L. C. Reddy, and R. S. Hiremath, "Performance Comparison of Wireless Mobile Ad Hoc Network Routing Protocols," IJCSNS International Journal of Computer Science and Network Security, vol. 8, no. 6, June 2008.

[10] P. C. Reddy, "Performance analysis of adhoc network routing protocols," Academic Open Internet Journal, ISSN 1311- 4360, vol. 17, 2006.

[11] S. R. Das, C. E. Perkins, and E. M. Royer, "Performance Comparison of Two On-demand Routing Protocols for Ad Hoc Networks," INFOCOM 2000, Tel Aviv, pp. 26-30 March 2000.

[12] P. Bakalis and B. Lawal, "Performance Evaluation of CBR and TCP Traffic Models on MANET using DSR Routing Protocol," IEEE International Conference on Communications and Mobile Computing 2010.

[13] The Network Simulator- ns-2. [Online]. Available: http://www.isi.edu/nsnam/ns/index.html.

[14] K. Fall and K. Vardhan. The VINT Project, UC Berkley, LBL, USC/ISI. [Online]. Available: from http://www.mash.cd.berkeley.edu/ns/. 


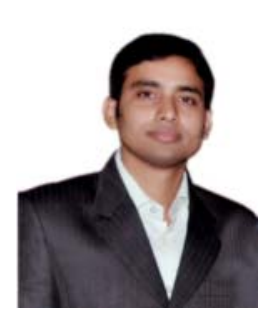

Manish Singh Chaudhary received B. Tech (samrath ashok technological institute, Who is an autonomous engineering College, Vidisha Madhya Pradesh year 2009), M. Tech in computer technology (from NIT Raipur) Chhattisgarh Year 2012. Presently working as a Software Engineer in Multinational National Company.

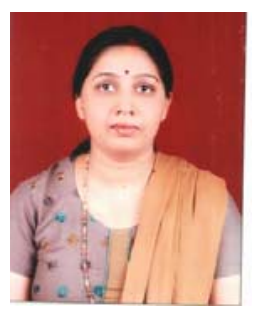

Varsha Singh received B. Tech (government engineering College, Bilaspur, Chhattisgarh year 1991), M.Tech in computer technology (government engineering College (Now NIT Raipur), Raipur Chhattisgarh Year 2002. Presently she is an assistant professor, Department of Electrical Engineering, NIT, Raipur, Chhattisgarh.

Presently, she is doing PhD from NIT Raipur. 